are rapidly recurring convulsive attacks, these should be met by rather large doses of bromide of potassium, and the same remedy in smaller doses is often very useful where there is a restless condition with more or less delirious wandering. In very many cases, however, no drugs will be required during this stage. The patient's condition must be carefully watched, and if it seems desirable to unload the bowels this may be often best accomplished by means of an enema. The state of the bladder must also be looked to, and the urine drawn off by a catheter if necessary.

For many days after the condition of unconsciousness bas wholly or partially passed away, the patient must still be kept as quiet as possible in body and $\min r$, and this rule more especially holds good where there is reason to believe that hæmorrhage has occurred. The diet and secretions must be carefully regulated, and in those exceptional cases in which there is very great difficulty in deglutition, the most prudent course for a time may be to feed the patient by means of a tube (to which a small funnel can be attached) passed through one nostril, and down as far as the commencement of the cesophagus. We may thus better secure rest for the damaged nerve-centres, and so contribute towards the patient's earlier recovery. And similarly where there is very great difficulty in articulation the patient should for a time be kept absolutely quiet, and not allowed to attempt to speak. A little later on, when there is less danger of inducing irritation at the seat of injury, the patient must be encouraged to swallow properly prepared food, and he must also be encouraged in his attempts to repeat or utter simple words. When the effects of the shock have thoroughly subsided, and when an amendment is beginning to take place, a judicious calling into play of weakened powers will, of course, materially assist in effecting their complete re-establishment.

3. One of the most important means of bringing about or of facilitating a return of power to the palsied limbs lies undoubtedly in a thorough attention to the general health of the patient. We must strive to rectify or mitigate general ill-health from whatsoever cause it may arise. We must see that the patient has easily-digestible and nutritious food, that he sleeps well, that he is freed as much as possible from all mental perturbation, and, as far as may be, surrounded by an atmosphere of general cheerfulness. These important measures should after a time be combined, in the majority of cases, with passive movements of the paralysed limbs, with frictions of the skin by means of a flesh brush or flannel, and with occasional volitional efforts to move the parts to which power is already returning-always bearing in mind that such attempts should stop short of the production of fatigue. Do not in the early stage resort to electricity; harm may be done by a too early faradisation of muscles, and, as for galvanisation of the brain (i. e., the passage of a galvanic current through the head), I would not counsel you to have recourse to it at any stage. An early adoption of such a method might do actual harm, and where it is had recourse to later, it is, to say the least, not likely to do any good. I am not aware of any sound principles upon which such haphazard attempts at amelioration could be recommended.

Where the paralysis has already existed for a long time, and the muscles are in a flaccid condition, the patient often derives great benefit from tonics in combination with minute doses of strychnia-beginning with one-thirtieth of a grain three times a day. And in such cases faradisation is often of the greatest service. It alters and improves the condition of the muscles, so that they become more capable of responding to weak volitional stimuli, which previously had no effect in calling them into activity.

Where a comparatively early contraction of the hand and wrist sets in, this ominous symptom may occasionally be arrested or retarded by cautious faradisation of the extensors of the forearm three or four times a week.

In those rare cases, moreover, in which an early wasting of the muscles of the paralysed limbs declares itself, much good may be done by faradisation. And we need have the less fear in resorting to such a measure, because there is good reason to believe that this process of early wasting is brought about under the influence of changes which have been secondarily induced in the spinal cord, rather than as an immediate result of any "irritative" influence emanating from the injury in the brain itself.

The same remark also holds good with respect to the causation of those nutritive changes which go to make up the pathological condition known as "late rigidity." And, as a consequence, these are best warded off by passive movements and frictions of the palsied limbs, combined with careful faradisation of the muscles. By these means we are most likely to exert a healthy influence upon the related parts of the spinal cord, and so do the best in our power to check the progress of degenerative changes in this centre, as well as those further changes in nerves, muscles, and joints which tend to follow or occur as concomitant events.

From my silence on the subject of specific remedies, gentlemen, you may have already gathered that we know of no drugs capable of curing a patient in whose brain a clot of blood is lying, or in whom a certain portion of this organ is destroyed by softening. We have to trust greatly to natural processes. Yet I hope you will have learned that by watchful care and attention we are able to do very much to assist or favour the action of these processes-by strict attention, that is, to symptoms as they arise, by looking well after the patient's general health, by a judicious rousing of the otherwise dormant functions of nerve and muscle, and generally by preserving him from all influences and measures which might prove actually harmful.

\section{NOTE OF A CASE OF RIFLE-SHOT WOUND OF THE ANKLE.}

Br THOMAS ANNANDALE, F.R.S.E.,

SURGEON TO THE EDINBURGH ROYAL INFIRMARY AND LRCTURRR ON CLINICAL SURGBRY.

U. $\mathrm{P}$ - aged thirty, was admitted into my wards in the Royal Infirmary on the 24th June, 1873, with the following history. Six months before, the patient, who was a fisherman, was engaged at sea with some others in fishing for salmon in a manner considered illegal, and, in consequence of some dispute with the authorities, his boat was fired into or at by a crew of one of H.M.'s gunboats. The shots fired were all blank cartridge except one, which contained the conical lead bullet used in the navy. This bullet passed through the side of the boat and then struck the patient on the left ankle, his thick fishing boot being pierced. He was shortly after seen by a medical man, who had the boat searched for any bullet which might have lodged in it. The result of this search was that a large portion of a bullet was found lying in the bottom of the boat. This portion, which is in my possession, is figured in the engraving at $A$. When his limb was examined soon after the accident, a small wound was found over the inner aspect of the lower end of the tibia, but a careful search failed to discover any body which had lodged. There was only this one wound. Suppuration of the soft parts surrounding the wound followed the accident, but after a few weeks the original wound healed, although several sinuses, the result of the suppuration, continued to discharge pus. When admitted there was found to be stiffness of the anklejoint, and three sinuses were observed over the internal malleolus. The skin in the region of these sinuses was undermined, but the probe could detect no foreign body.

A consideration of the case, which appeared to me to resemble in some respects that of the famous Italian patriot, led me to remark to my students and others who saw the case, the great probability that the bullet or a portion of it had penetrated and lodged in the bone. I came to this conclusion-(1) knowing the nature of the body which caused the injury; (2) from the fact that there was only one wound caused by the injury; (3) because the nonbealing of the sinuses pointed to some foreign body, or local source of irritation.

On the following day, June 25th, the patient being put under the influence of chloroform, I opened up the sinuses, so as to expose the lower end of the tibia, and after a little search discovered a small opening in the bone. Having, by means of the bone forceps, enlarged this opening so as to introduce the finger, I at once detected a foreign body firmly wedged in the cancellated texture of the lower end of the bone. No splitting or fissuring of the surrounding bone 
could be detected. The foreign body, being seized with the forceps, was, after a little manipulative movement, removed, and was found to be the larger portion of a bullet, twisted and distorted as is well illustrated in the woodcut $\mathrm{B}$. No bad
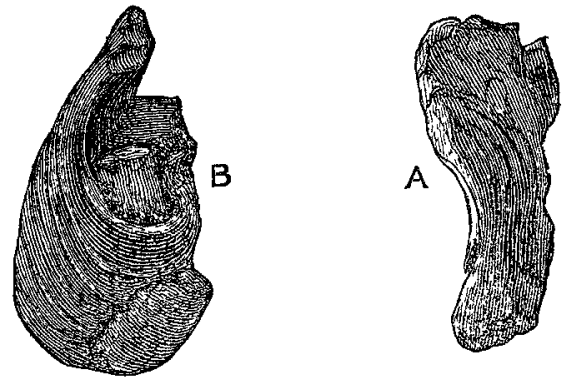

results followed the operation, and the patient was dismissed on July 29th with the wound and sinuses soundly healed.

Remarks. - The portion of bullet extracted from the bone in this case and that found in the boat, when weighed together, amounted to a little less than a whole bullet which I obtained from a naval officer; and as the history of only one ball cartridge having been fired was very distinct, it is most probable that the two portions formed the bullet which injured the patient. His case therefore is an illustrative example of the splitting of a bullet on coming in contact with a hard substance, which, in the present instance, was most likely to have been some part of the boat or the patient's thick boot; and it is also a good proof that a conical ball, or a portion of it, may penetrate and lodge in a bone without fracturing its entire thickness or causing fissuring of it. The probable explanation of the lodgment of the bullet without other injury of the bone is that its force had been considerably spent before it struck the patient.

Edinburgh.

\section{A CASE OF MALE HYSTERIA.}

By JOHN CAVAFY, M.D., ASSISTANT-PHYSICIAN TO BT. GEOBGE'S HOSPITAL.

J. H-, aged thirty-seven, shoemaker, came under my care as an out-patient at St. George's Hospital on Nov. 20th. He stated that for the last sir months he had noticed that his urine, which was passed clear, became quickly turbid after standing, with formation of a thick white deposit. There was at first no pain, but for the last month he had suffered from repeated headaches and pain in the back. He had never noticed blood in the water, and increased frequency of micturition, scalding, and suprapubic pain bad been absent throughout. The man was well nourished, and of healthy aspect, but his manner was decidedly peculiar; he spoke quickly and excitedly, had a very frequent and rather spasmodic smile, and before commencing his recital he unlocked a large bag from which he withdrew two large bottles containing specimens of his water, which he placed upon the table with an air of triumph. One of these was reported to be three days old, the contents of the other were stated to have been passed the same morning.

Both specimens were strongly alkaline, with a pure and purgent, but not in the least putrid, ammoniacal smell, and in each there was a copious, heavy, white sediment, which was most plentiful in the older specimen. A portion of the clear supernatant liquid was tested by the addition of nitric acid. No precipitate was produced, but there was a very strong effervescence, which was just as decided with hydrochloric and acetic acids; the mixture bubbled up as violently as champagne, and overflowed the test-glass. The sediment effervesced still more strongly, the greater part of it dissolving, but leaving a very preceptible insoluble residue. On microscopic examination it was found to contain a small quantity of granular amorphous matter, but was chiefly crystalline. There were a few crystals of triple phosphate, and urate of ammonia was plentiful; but the greater part consisted of transparent colourless mostly feathery crystals, some few boot-jack forms, and a few which closely resembled the whetstone and small-tooth-comb shapes of uric acid.
There was no trace of pus or blood. On Nov. 27 th he came again, with his bag and simper, and produced two bottles of urine, one passed the day before, and the other the same morning, according to his statement. They were of precisely the same chemical character as the previous ones, and the microscope showed the same crystals; but, in addition, two pieces of striped muscle, in the single slide examined. He was now asked to pass some urine before us, which he did with perfect readiness. It was clear, pale, and distinctly acid. A portion of this was mixed with an equal bulk of strong nitric acid and set aside in a cold place till next day; there was no crystallisation of nitrate of urea. The rest was placed in a clean bottle, which was kept uncorked for a fortnight. No sediment was found, no ammoniacal odour was developed, but in its place there was the normal foul smell of putrescent urine.

The addition of extraneous matter to urine for purposes of deceit is not uncommon; chalk and sand have been so added, and in one case which came under my own observation, an old woman produced a dark greenish-brown tint and deposit by powdered aloes. As a rule such cases are not difficult to recognise, but here the distinct orystalline form of the deposit led me at first to suppose that it was naturally developed, and that the comparatively enormous quantity of carbonates and ammonia present were due to the exceptionally rapid decomposition of a large excess of urea, which, as Dr. Fuller has pointed out, is often present in large quantity in the urine of nervous patients. But as no crystallisation took place on the addition of nitric acid to the fresh urine, this supposition fell to the ground. The patient's manner was suspicious, and finally the bits of muscle in one portion of the sediment, and especially the fact that the urine kept by myself underweut no such change as he described, were, in my opinion, sufficient to justify the diagnosis of hysteria. Some may, perhaps, prefer to call the case malingering; but a malingerer has usually some distinct object to gain, such as money, or the food and comfort of a ward. These motives are, of course, absent in out-patients, and the man did not even ask for a certificate. What matters were added by him I am unable to say, but it is possible that a plentiful supply of smelling-salts and a little beef-tea or Liebig's extract would produce similar results, should anyone think the experiment worth trying.

\section{Aftlodical Sorieties.}

\section{MEDICAL SOCIETY OF LONDON.}

ThIs Society met on the 14th inst., Mr. Gant, vicepresident, in the chair. The evening was taken up by an elaborate paper on Cleft Palate, by Mr. Wirliam Rose, which provoked an animated discussion. Mr. Rose illustrated his paper by the exhibition of a patient, aged twenty three, on whom he had, three months ago, successfully operated for a fissure extending through the soft and hard palates to within half an inch of the alveolar ridge. After treating of the subject of arrested development of the upper jaws (of which diagrams were given), and suggesting a plan of bringing the maxillæ together immediately after birth in cases of very wide cleft, he proceeded to describe minutely Sir William Fergusson's new method of operating for securing simultaneous closure of a fissure in the hard and soft palates, by boring holes through the margin of the hard palate for the passage of the threads, and then cutting through it with a chisel in a line parallel to and about half an inch from the edge of the cleft; the borders of the cleft in the hard palate by this means could be approximated, when, after dividing the levator palati muscles and carefully paring the edges, stitches could be passed through the holes in the hard and through the soft palate, and the edges brought into apposition in the median line. (The operation was illustrated by drawings. Mr. Rose also demonstrated a new way of passing the threads.) He went on to speak of Sir William Fergusson's introduction of myotomy thirty years ago in the treatment of fissure of the solt palate as having quite revolutionised staphyloraphy, and ex$\mathrm{CO} \mathbf{2}$ 